\title{
EL MAGNICIDIO DE TLAXCALANTONGO EN LA PRENSA MADRILEÑA
}

\author{
Antonio LoRente Medina \\ UNED \\ alorente@ flog.uned.es
}

\section{RESUMEN}

Este trabajo desarrolla dos ideas fundamentales: las causas de la caída y muerte de Venustiano Carranza, como consecuencia de su intervención en las elecciones presidenciales de 1920; y la repercusión que este hecho tuvo en la prensa española, mediatizada por la procedencia de las agencias internacionales de información. Los periódicos españoles recogieron con bastante fidelidad los dramáticos sucesos que concluyeron con el magnicidio de Tlaxcalantongo en la madrugada del 21 de mayo de 1620, aunque sus artículos de opinión estén teñidos de una visión abiertamente anti-estadounidense.

Palabras Clave: Revolución Mexicana, elecciones, magnicidio, Carranza, Pablo González y «la Trinidad de Sonora»: Obregón, De la Huerta, Calles.

\section{AbStRact}

This paper develops two fundamental ideas: the causes of the decline and death of Venustiano Carranza, as a result of their participation in the presidential elections of 1920; and the impact this had on the Spanish Press, influenced by the source of International News Agencies. Spanish newspapers picket up fairly closely the dramatic events which led to the assassination of Tlaxcalantongo on the morning of may 21, 1920, although his opinion pieces are dyed an openly anti-American vision.

Keywords: Mexican Revolution, elections, assassination, Carranza, Pablo González, and «Trinity of Sonora»: Obregón, De la Huerta, Calles. 
En la madrugada del veintiuno de mayo de 1920 perdía la vida el Presidente de México, don Venustiano Carranza, en una mísera choza del jacal de Tlaxcalantongo, en el estado de Puebla. Acababa así un largo proceso político que se había iniciado un año antes, cuando el general Obregón se postuló a la Presidencia de la República y, unos meses después, lo secundaba el general Pablo González.

La autoridad de Carranza, indiscutida hasta este momento, fue sufriendo desde entonces un continuo deterioro, como consecuencia de un cúmulo de circunstancias que culminaron con la pérdida efectiva de su poder entre finales de 1919 y primeros meses del año siguiente. Sin afán de pormenorizar, recordemos las más importantes ${ }^{1}$ :

1.- El descontento general que prendió en el sistema educativo nacional, tanto entre el profesorado, que sufrió un despido colectivo que lo enfrentó a la política oficial gobiernista y del que se hizo eco la prensa y la opinión pública mexicana, como entre los alumnos, desde la enseñanza primaria hasta los egresados de la universidad. La puesta en marcha de numerosos recortes en las ayudas, el giro hacia una política educativa represiva que expulsó a muchos estudiantes de sus lugares de estudio, acusados de sedición, y la supresión de becas destinadas al estudio en el extranjero puso en pie de guerra a toda la comunidad educativa. $Y$ la exasperación alcanzó cotas notables cuando constataron que dichas restricciones no alcanzaban a los estudiantes allegados al gobierno.

2.- A lo largo de este año, pareció que Carranza le volvía la espalda a los trabajadores. Es cierto que don Venustiano nunca había sido un revolucionario, pero la caída en picado de los salarios rurales y las continuas huelgas obreras de 1919 atestiguan la creciente intranquilidad del proletariado mexicano y el estado de inestabilidad y de agitación social que caracterizó el final de su mandato. La pérdida de contacto con las masas provocó que muchos trabajadores vieran en Obregón una esperanza de mejora real y depositaran en él su lealtad. Simultáneamente la CROM y el movimiento ferrocarrilero — que estaba en manos de los militares, no lo olvidemos - lo apoyaron en masa.

3. De igual modo, los diversos proyectos de reforma agraria se habían paralizado de hecho, como consecuencia de los numerosos privilegios que habían surgido a la sombra de la administración de las tierras confiscadas, o de bienes intervenidos, y de las múltiples cláusulas restrictivas que su gobierno había dictado para restringir al máximo la petición de tierras por parte de los campesinos.

4.- El afán permanente de Carranza por congraciarse con los miembros del ejército que le simpatizaban desembocó en un compadrazgo que posibilitaba el que muchos generales se lucraran de forma ilegal con la connivencia del Presidente. La corrupción en el ejército creció de manera exponencial, a la par que el grado de impunidad de los generales en sus acciones, que, si siempre habían mantenido su independencia efectiva respecto del ejecutivo, en estos momentos se llegaron a creer que ellos - y no el gobierno- eran los verdaderos representantes de la voluntad nacional. Paralelamente, y de forma insensible, fue acentuándose en el seno de la sociedad mexicana la idea de que el carrancismo

\footnotetext{
${ }^{1}$ Es básico para estos antecedentes el libro de Richmond, 1986, pp.297-309.
} 
constituía una verdadera lacra social ${ }^{2}$. El verbo «carrancear» se convirtió en sinónimo de «robar», hasta el punto de que, en un intento de salvaguardar la figura del Presidente, sus allegados acuñaron la célebre frase de que «El Viejo deja robar, pero no roba», que se contesta por sí misma y que ya fuera refutada brillantemente por Vasconcelos en La tormenta ${ }^{3}$.

5.- El giro en su política exterior, a favor de un estrechamiento entre las relaciones comerciales con los Estados Unidos, sorprendió desagradablemente a muchos de sus seguidores nacionalistas. Es verdad que este hecho vino impuesto por las circunstancias. La derrota de Alemania en la Primera Guerra Mundial obligó al gobierno mexicano a comerciar casi en exclusiva con los mercados estadounidenses. Pero muchos partidarios suyos, entre los que se encontraba un considerable número de empresarios mexicanos, se sintieron traicionados por el cambio de su política internacional.

Todos estos hechos motivaron que la popularidad de Carranza se encontrara bajo mínimos a finales de 1919. Con todo, su autoridad se hubiera mantenido hasta el final de su mandato si no hubiera intentado imponer la candidatura del Ignacio Bonillas como su sucesor a la Presidencia de la República ${ }^{4}$, contraviniendo su promesa de que las elecciones de 1920 serían justas y abiertas, y a pesar de la enorme impopularidad de su candidato, posiblemente porque creía en la necesidad de fomentar un candidato civil. Es verdad que en una proclama Carranza había pedido calma a la nación y había afirmado que al término de su Presidencia se retiraría a la vida privada; pero a los ojos del país sus actos mostraban que estaba decidido a mantener el control del poder ejecutivo. No obstante la evidencia del rechazo que el ex-embajador de México en Estados Unidos provocaba en la opinión pública mexicana, que jocosamente lo bautizó con el seudónimo de «Flor de té», y la convicción de que actuaba a las órdenes del Presidente, Carranza no escatimó esfuerzos ni gastos para asegurarle la victoria, que, para mayor escarnio, se hacían sobre un candidato «in absentia», porque Bonillas no regresó a México hasta marzo de $1920^{5}$ y sin tiempo casi para aceptar servilmente la candidatura de débil Partido Liberal Democrático.

Así las cosas, la campaña contra el candidato civilista se convirtió, parafraseando a Richmond, «en una farsa cruel». Circularon abundantes chistes en los que se le satirizaba ferozmente, presentándolo como «Mister Bonillas». Con ello se hacía alusión a su matrimonio con una ciudadana norteamericana, a su posible olvido de la lengua materna en favor de la lengua inglesa, a su hipotética ciudadanía estadounidense, e incluso a

${ }^{2}$ Hay numerosos testimonios conocidos por todos en la «Novela de la Revolución», como para que ahora los subrayemos. Si recuerdo en estos momentos Las tribulaciones de una familia decente, de Mariano Azuela, es porque se publicó en el momento de máximo esplendor del carrancismo: en el año 1918.

3 Vasconcelos, 1958, pp. 279-290: «El balance carranclán». Para este punto concreto, p. 290.

${ }^{4}$ Que Bonillas fue un candidato de última hora en el que no se había pensado nunca lo muestra el hecho de que Carranza pensó, en un primer momento, que el candidato civilista fuera don Luis Cabrera, político experimentado y de prestigio; pero Cabrera, que había perdido hacía poco a uno de sus hijos, declinó cortésmente la propuesta. Incluso el propio Bonilla creía un año antes de que se precipitaran los acontecimientos, y así lo publicó en la prensa, que sólo habría dos candidatos presidenciales: Obregón y González (Galveston Daily News, 7 de junio de 1918, p. 3).

${ }^{5}$ El 23 de marzo de 1920 Wenceslao Blasco refiere la entrada de Bonillas en México el 21 de marzo, aunque el artículo no se publicó en el $A B C$ hasta el 21 de abril, p. 7. 
su presunta profesión de sheriff en Texas, con la clara intención de atraer sobre él la animadversión de los nacionalistas mexicanos. Carranza tampoco permaneció inactivo. En su pretensión de debilitar a Obregón, transfirió a los obregonistas claves de Sonora a otros estados de la República e hizo lo mismo con los burócratas y militares favorables al carismático general. En el caso de los últimos, los sometió a un acoso por toda la nación que concluyó en arresto ilegal, como amargamente se quejaba Obregón en una carta que le dirigió el 23 de marzo de $1920^{6}$.

El desencadenante final de la tragedia lo constituyó un doble movimiento simultáneo de parte de Carranza: por un lado, intentó encarcelar a Obregón, so pretexto de una pretendida alianza de éste con un general felicista (11 de abril de 1920); por otro, la fricción con el gobierno del estado de Sonora, presidido por Adolfo de la Huerta, uno de los más decididos partidarios de Obregón, que concluyó con el envío de tropas federales al mando del general Diéguez, con la pretensión de cerrar la frontera con Estados Unidos. Ambos movimientos resultaron fallidos. En el primer caso porque Obregón salió tranquilamente de México con la ayuda de los ferrocarrileros y de la CROM para, ya en Guerrero, unirse al movimiento insurreccional y dirigirlo. En el segundo caso porque el general De la Huerta consideró la actuación de Diéguez como una violación de la soberanía de su estado y, con la ayuda de Calles ${ }^{7}$, publicó el Plan de Agua Prieta, en el que desconocía a Carranza y lo culpaba de los numerosos intentos de manipular las próximas elecciones electorales.

Las consecuencias que estos hechos tuvieron en Carranza y sus seguidores no pudieron ser más desastrosas: un mes después del Plan de Agua Prieta Obregón se había convertido de facto en el nuevo gobernante de México; Carranza había perdido la vida y sus seguidores estaban derrotados, encarcelados o en el exilio.

Pero, ¿cómo se reflejaron estos hechos en la prensa española? Véamoslo a continuación.

Por regla general las noticias recogidas en Madrid presentan una gran uniformidad, hasta en sus encabezados; lo que no tiene nada de extraño, dada la procedencia de las fuentes de información: la Agencia Americana y, en menor medida, la Agencia Radio. Una y otra se hacen eco de las noticias que circulan en distintos lugares, que transmiten sus corresponsales, enviados a México, Nueva York, Washington, El Paso, Veracruz, La Habana o Londres, y transfieren los cablegramas a los distintos periódicos que constituyen su cartera de clientes. Éstos las imprimen según les van llegando en distintos breves que se yuxtaponen y, a veces, se contradicen, por mor de informar a sus lectores con la mayor celeridad posible ${ }^{8}$.

\footnotetext{
${ }^{6}$ Fabela, I., y Fabela, J, (1960-1973), vol. 18, p. 375.

7 El 6 de junio, p. 6, el $A B C$ publica el artículo de Wenceslao Blasco ( «a Revolución en Sonora») de abril de 1920, en el que se extractan los telegramas que se cruzan Calles y Diéguez por esta causa.

${ }^{8}$ En algún caso, el periodismo madrileño muestra un claro sesgo antiestadounidense, como ocurre con la Ilustración Española y Americana, que el 20 de abril de 1920 decía en el artículo de Alfonso L. Sarralbo, titulado «Vida americana» (p. 12): «...se adivinan los secretos directores de la última revolución mejicana, de la cual no sabemos otras noticias que las venidas por conducto yanqui, y, por ende, de todo inexactas o al menos tendenciosas». Y ocho días después afirmaba el mismo: ¿quién, sino Yanquilandia, atiza el fuego de la guerra civil de Méjico? ¿Quién, más que ella, secuestra el cable para comunicar noticias falsas o tendenciosas acerca del desarrollo de los acontecimientos bélicos en esa desgraciada República? De ahí que las callemos» (p. 13).
} 
En cualquier caso, se percibe desde el primer momento en la prensa española un contraste entre la rapidez de acción que caracteriza a los rebeldes y el enquistamiento del gobierno central y su obstinación por considerarlos fuera de la ley. Ya el 15 de abril de 1920 los periódicos madrileños dan cuenta de la movilización general en Sonora ${ }^{9}$, y un día después del envío de un barco con armas a Yucatán, a favor del general Alvarado ${ }^{10}$, así como de barruntos de levantamientos en catorce estados, negados sistemáticamente desde el lado carrancista, que los califica de noticias tendenciosamente propaladas por la prensa estadounidense ${ }^{11}$. Todavía el 24 de abril El Siglo Futuro recoge unas declaraciones del gobierno de Carranza, en las que se afirma que todas las noticias transmitidas desde Estados Unidos son falsas, que no hay tales triunfos revolucionarios. Y su embajador en Washington, no obstante aceptar lo evidente, que la insurrección se ha extendido a varios estados, asegura «que la represión de esta revuelta es cuestión de horas» ${ }^{12}$. Lo curioso es que no será hasta esta fecha cuando el gobierno decrete la suspensión de garantías, como paso previo a la proclamación de la Ley Marcial.

Paralelamente, los rebeldes parecen ganar posiciones en la guerra de propaganda que se cruzan con el gobierno federal, puesto que todos los periódicos sin excepción subrayan que el origen de la sublevación está en la decisión de Carranza de mandar tropas federales al Estado de Sonora, sin el consentimiento de las autoridades de dicho estado ${ }^{13}$, que lo consideran un atentado contra su soberanía. En verdad el envío de un cuerpo de ejército al mando del general Diéguez supuso una verdadera agresión del Estado contra la autonomía del gobierno de Sonora, porque Diéguez cerró la frontera con Estados Unidos con la intención de impedir el flujo natural de los aún hipotéticos rebeldes ${ }^{14}$, aunque Carranza, siguiendo su habitual costumbre de revestir con un manto de legalidad sus decisiones políticas, lo quisiera limitar a una simple discusión constitucional, que podía dirimirse en el ámbito del Tribunal Constitucional, que él manejaba a su antojo. De ahí su insistencia desde el comienzo del conflicto en considerar «facciosos a los miembros de la Asamblea del Estado de Sonora», así como a todas las personas que tomaran parte «en el movimiento separatista», y que en un mensaje de contestación al gobierno de Sonora se escudase en que el Ejército Nacional «tiene la misión de proteger la Soberanía de la República» ${ }^{15}$, como si sus primeras fricciones con Sonora, meramente económicas,

9 15-IV-1920: La Correspondencia de España, p. 2; La Época, p. 1; El Siglo Futuro, p. 1. El 16 de abril recogen estas noticias El Sol, p, 9; y La Libertad, p. 3.

1016 de abril: ABC, p. 18; La Correspondencia de España, p. 2; La Época, p. 1; y El Sol, p. 9.

1116 de abril: $A B C$, p. 18; La Correspondencia de España, p. 2; La Epoca, p. 1. 18 de abril: El Sol, p. 7. 23 de abril: El Sol, p. 7. 24 de abril: El Siglo Futuro, p. 7. Y aún el 30 de abril, cuando ya se vislumbraba el desenlace final del conflicto, se afirma en Vida Marítima, p. 4: «de la revolución de Méjico tenemos noticias contradictorias, ofreciéndose agravadas las de origen norteamericano y calificando éstas de tendenciosas el gobierno de Carranza».

${ }^{12}$ El Siglo Futuro, p. 2. La Legación Mexicana en España había evacuado una noticia similar el día anterior en $\mathrm{El} \mathrm{Sol,} \mathrm{p.} 7$.

1315 de abril: La Correspondencia de España, p. 2; La Época, p. 1; El Siglo Futuro, p. 1. 23 de abril: El Sol, p. 7; y La Libertad, p. 3.

${ }_{14} \mathrm{Y}$ buena prueba de que ésta era su finalidad nos lo ofrece el hecho de que la primera medida que toma el gobierno federal, nada más iniciada la rebelión, es cursar una petición al gobierno estadounidense para poder cruzar las tropas federales la frontera y atacar por la retaguardia a las fuerzas sonorenses. Petición recogida el 18 de de abril, por $A B C$, p. 17 y El Sol, p. 7.

1523 de abril: ABC, p.14; El Siglo Futuro, p. 7; 24 de abril: La Correspondencia de España, p. 1; y El Globo, p. 2. 
hubieran podido hacer peligrar dicha soberanía. Tampoco es gratuita la denominación de «movimiento separatista». Posiblemente quería movilizar en su favor a los nacionalistas mexicanos ante el peligro de una nueva segregación del territorio nacional, similar a la acaecida con Texas el siglo anterior ${ }^{16}$. En cualquier caso, la opinión pública mexicana sabía con claridad lo que se estaba discutiendo en estos momentos y no cayó en esa provocación, aunque el general Calles se sintiera en la obligación de salir al paso de ella aclarando que la independencia de Sonora era la respuesta a la dictadura impuesta por Carranza y que Sonora volvería a reconocer al gobierno revolucionario en cuanto que el Presidente depusiera su actitud ${ }^{17}$.

En medio de combates con resultados difícilmente verificables ${ }^{18}$, del trasvase permanente de contingentes militares al bando rebelde ${ }^{19}$ y del intento infructuoso de algunos políticos por mediar entre ambas facciones ${ }^{20}$, la lógica de la acción bélica se va imponiendo. A finales de abril de 1920 los éxitos militares de los rebeldes, que desde el principio tuvieron la adhesión de Villa, se van haciendo cada vez más evidentes: el 28 de abril la prensa notifica que las tropas federales del Estado de Sinaloa se baten en retirada y que el general Alvarado amenaza con sus tropas las montañas próximas a México $^{21}$. Y el día siguiente anuncia la caída de las ciudades Mier, Guerrero y Tamaulipas en poder de las fuerzas de Sonora ${ }^{22}$.Una semana después la situación para Carranza y los suyos empieza a ser angustiosa en México. Prácticamente el Norte del país está en manos de los rebeldes, con la excepción de Chihuahua, hacia donde envía Calles un contingente de seis mil soldados; Tampico está a punto de rendirse a Obregón, que amenaza a Puebla y México. Y la situación se agrava cuando el general Pablo González, reconocido como uno de los más decididos defensores de Carranza, rompe definitiva-

${ }^{16}$ Se hace eco de esta posibilidad la revista España, 24 de abril, p. 7, cuando recoge los anhelos del inefable Lane Wilson porque Sonora se convirtiera en un nuevo Texas, recogido en un periódico texano, que no cita.

17 El Sol, 23 de abril, p. 7; El Siglo Futuro, 24 de abril, p. 2.

1818 de abril: $A B C$, p. 18; El Sol, p. 7, y La Época, 19 de abril, p. 1, se hacen eco de una posible derrota de las fuerzas sonorenses en Sinaloa. Y el segundo de ellos habla del levantamiento del coronel Rubio, gobernador de Michoacán, y del envío, por parte del gobierno, federal, de un destacamento en su persecución. Unos días después (23 de abril: La Época, p. 1, y El Siglo Futuro, p. 1; 24 de abril: La Correspondencia de España, p. 1, El Globo, p. 1, y El Sol, p. 7) ya se habla de fuertes combates entre Pascual Rubio y el general Bruno Neira, así como de la derrota de Neira y del acoso de sus tropas por los partidarios de Obregón, mientras Carranza pone precio a la cabeza del gobernador de Michoacán. El ABC, 26 de abril, p. 7, llega a decir que se han rendido los Jefes Revolucionarios a Carranza.

${ }^{19}$ El 16 de abril La Época, p. 1, anuncia que el general Gómez, en San Luis Potosí, se ha pasado a los insurrectos; el 19 de abril que Pascual Rubio se ha levantado en Michoacán. Para el 24 de abril (El Siglo Futuro, p. 2) se han unido a Sonora Sinaloa, Zacatecas, Morelos, Hidalgo y Tlaxcala. Y el 28 de abril los famosos destacamentos Robiloff se han pasado también a Obregón (La Época, p. 1).

${ }^{20}$ El mismo día 15 de abril La Correspondencia de España, p. 1, y El Siglo Futuro, p. 1, recogen la petición de audiencia a Carranza por parte de Roberto Pesqueira para mediar en el conflicto. El 24 de abril La Época, p. 1, habla de un intento de Carranza de entablar negociaciones con los rebeldes, al que contesta Alvarado, representante de los sonorenses en Washington, diciendo «que esa gestión ha llegado demasiado tarde». Y dos días después este mismo periódico avisa de la llegada de dieciocho parlamentarios congresistas a Agua Prieta con el fin de conseguir un acuerdo entre los sonorenses y el gobierno central. Por fin, El Globo (30 de abril, p. 2) aclara que todos los indicios «parecen indicar que no se llegará a un acuerdo entre los rebeldes y el gobierno del general Carranza».

${ }_{21}^{2}$ La Época, 28 de abril, p. 1.

${ }^{22}$ La Época, p. 2; La Libertad, p. 3; y El Sol, p. 7. 
mente con él ${ }^{23}$ tras fracasar en su intento de conseguir que el Presidente anulara la imposición de Bonillas como candidato civilista a la Presidencia de la República. El 2 de mayo se reúne con sus tropas en Morelos, corta las vías férreas entre México y Veracruz y amenaza por el sudoeste la capital. El peligro inminente de ser copados en la propia ciudad de México lleva a los militares fieles a Carranza - Murguía, Salinas, Urquizoa aconsejarle el abandono de la capital ${ }^{24}$. Pero antes de marcharse Carranza ordena la ejecución de los presos políticos y militares adictos a Obregón que se encontraban en la prisión de Santiago de Tlatelolco ${ }^{25} \mathrm{y}$, decidido a sostenerse, publica su «Manifiesto a la Nación» (5 de mayo de 1920) en el que resume de forma brillante y sesgada el origen de las disputas por la Presidencia entre Obregón y González, la «aparición» de Bonillas — apoyado por el Partido Civilista, no por el gobierno- la «abierta rebelión» de Obregón y la «enmascarada» de González ${ }^{26}$. Y concluye su argumentación afirmando resueltamente: «Considero como un deber aniquilar a los revoltosos y no cejaré hasta que lo haya conseguido».

El gobierno, siguiendo las directrices de la mayor parte de sus consejeros militares ${ }^{27}$, decide marchar hacia Veracruz, entre el pánico y la confusión de sus fieles subordinados, que sienten la proximidad de las fuerzas de Pablo González en las inmediaciones de la capital. En veinticuatro horas se organiza la partida, compuesta por un conjunto abigarrado de trenes, entre los que se encuentra el tren presidencial, con su aparato burocrático, y sus allegados y familiares, trenes con numerosos archivos vitales para su gobierno, dinero de la Hacienda Pública y todo el armamento, municiones y caballería que se pueden llevar en tan escaso tiempo. Les acompaña una columna de cinco mil soldados al mando del general Murguía. Y lo escoltan y van abriendo camino fuerzas de infantería y de caballería procedentes de la División Suprema, encargada de defender la capital. Pero los problemas se le amontonan desde el comienzo: los ferroviarios sabotean durante siete horas la salida del convoy, dando tiempo a que las vanguardias enemigas envíen una máquina loca contra la retaguardia del último tren, que obstruye la salida de varios trenes de tropas, de armamento y de intendencia ${ }^{28}$ en Villa Guadalupe. Como consecuen-

${ }^{23}$ Taracena, 1963, p. 296. Su opinión favorable a Pablo González no es suscrita por ningún otro estudioso. Véase al respecto Cabrera, 1975, vol. III, pp. 521-523; Urquizo, 1931 y 1959, y Carranza Castro, 1972, pp. 502-517. El cuartelazo de González fue subrayado unánimemente por la prensa española: 6 de mayo: $A B C$, p. 15, La Época, p. 1, Acción, p. 3; El Siglo Futuro, p. 1; 7 de mayo: El Globo, p. 3, La Libertad, p. 1.

${ }^{24}$ La Correspondencia de España, 6 de mayo, p. 6, y 8 de mayo, p. 2; 7 de mayo: El Imparcial, p. 1, El Siglo Futuro, p. 1; 9 de mayo: El Imparcial, p. 1, El Sol, p. 1; y 11 de mayo, El País, p. 2.

2511 de mayo: El Siglo Futuro, p. 1, El País, p. 2, La Libertad, p. 1, La Acción, p. 1; 12 de mayo: La Correspondencia de España, p. 1, La Época, p. 3, y El Globo, p. 3. No está claro esto. Wenceslao Blasco lo desmiente en su crónica del 18 de mayo, publicada en $A B C, 24$ de mayo, p. 7.

${ }^{26}$ Puede leerse ahora en Gobierno de Coahuila, 1995, pp. 285-292. Alusiones al manifiesto hay en $L a$ Correspondencia de España y en El Siglo Futuro (7 de mayo, p. 1), El Heraldo de Madrid y El Globo (8 de mayo, p. 1); y en El Sol, 9 de mayo, p. 1.

27 Al parecer, con la opinión en contra de Urquizo, que lo considera un disparate logístico. Según Carranza Castro, 1972, p. 505, en un principio se pensó en trasladar al gobierno a algún lugar del Norte de la República. Pero dicha opción fue desestimada por la marcha a Veracruz cuando se recibió el telegrama de Cándido Aguilar, en el que se comunicaba que parte de su guarnición se le había sublevado. Pudo entonces más la idea de sofocar la sedición, ayudando a Aguilar, y hacerse fuertes en tan importante puerto, abierto al comercio internacional.

${ }^{28}$ Carranza Castro, 1977, p. 522. Noticia que recoge $A B C, 18$ de mayo, p. 7: «el choque pavoroso de uno de los trenes de la comitiva, con una máquina loca, que en velocidad vertiginosa vino a caer sobre uno de los convoyes». 
cia de ello la poderosa columna pierde la artillería, el material de la fábrica de armas, el parque sanitario, los caballos y las tropas de infantería Supremos Poderes, antes de poder contactar con el enemigo y queda mermada sensiblemente para combatir. No tiene nada de extraño por eso, que Cabrera escribiera poco después del desenlace final que «desde su salida de México, Carranza estaba derrotado» ${ }^{29}$.

Con todo, Carranza abandona México con la esperanza de poderse recuperar en Veracruz y confiado en que se entable una lucha por el dominio de la capital entre obregonistas y pablistas que posibilite su regreso triunfal. En principio sus previsiones parecen cumplirse. Un día después de su salida de la capital La Época, El Imparcial y El Sol revelan fuertes desavenencias entre Obregón y González por la Presidencia de la República $^{30}$. Para el 14 de mayo la rivalidad entre ambos es manifiesta y se reproduce en casi toda la prensa madrileña ${ }^{31}$; pero cuatro días después Pablo González sorprende a todo el mundo anunciando que renuncia «por patriotismo» a la Presidencia de la República y que se adhiere a la causa de Obregón ${ }^{32}$, perdiendo Carranza la única baza importante que le quedaba. Desconocemos las razones que movieron a Pablo González a renunciar a la Presidencia de la República. Sin descartar del todo posibles motivos patrióticos, satirizados irónicamente por Cabrera, debió de pesar mucho en su renuncia su convicción de la escasa reputación que su persona tenía en el ejército, como afirmara Vasconcelos ${ }^{33}$ en La tormenta.

El viaje de Carranza a Veracruz se convierte, así, en una expedición hacia el fracaso, hostigado permanentemente el gobierno por fuerzas enemigas que lo rodean y que estrechan cada vez más el cerco, en un territorio adverso con gente indiferente, cuando no hostil, y con continuas deserciones que quebrantan la moral de los soldados que permanecen fieles. En Esperanto tienen que abandonar la mayoría de los trenes por carencia de agua y de combustible. El 12 de mayo un emisario del general Treviño lleva el ultimátum que envían Obregón y González a Carranza, concediéndole cuatro horas para que se rinda a cambio de ofrecerle una escolta que lo acompañe y vele por su vida hasta Veracruz $^{34}$. De lo contrario Treviño tiene órdenes de atacar con todos sus efectivos y hacer prisioneros «desde Murguía hasta el último ciudadano que haya opuesto resistencia». Carranza rechaza las condiciones, que considera «una limosna humillante ${ }^{35}$, pero que dan idea de la frágil situación en que se encontraba. Todavía los carrancistas consiguen vencer a partidas enemigas en Rinconada y Aljibes; pero tras el último combate advierten que han peleado contra las fuerzas veracruzanas del general Guadalupe Sánchez y

${ }^{29}$ Cabrera, 1975, vol. III, pp. 441- 545. Para este punto concreto, p. 523.

309 de mayo: La Época, p. 1, El Imparcial, p. 1, El Sol, p. 1; 11 de mayo: EL Globo, p. 1.

3113 de mayo: $A B C$, p. 20, La Época, p. 2, El Imparcial, p. 1; 14 de mayo: ABC, p. 14, El Siglo Futuro, p.1, La Correspondencia Militar, p. 2; Libertad, p. 5.

${ }^{32}$ Ya La Época, 17 de mayo, p. 3, anticipa la noticia de que están solucionadas las diferencias entre ambos generales. Al día siguiente el Heraldo de Madrid, p. 1, informa de la renuncia de Pablo González. El anuncio de esta renuncia se conoció en México el mismo día 15.

${ }_{33}$ Vasconcelos, 1958, p. 365, nunca creyó que si González hubiera seguido fiel a Carranza el Plan de Agua Prieta no hubiera triunfado, porque «la impopularidad de Carranza era total y en el ejército no tenía arrastre alguno el pablismo».

${ }^{34}$ El Siglo Futuro, 11 de mayo, p. 1; 12 de mayo: La Época, p. 3 y El Imparcial, p. 2; 13 de mayo: El Imparcial, p. 1 y El Sol, p. 7; y 14 de mayo, El Globo, p. 3; 24 de mayo: ABC, p. 7.

35 Cabrera, 1975, vol. III, p. 525. 
se sienten «irremisiblemente perdidos» ante el inminente ataque enemigo, muy superior en número y moral ${ }^{36}$. Por esta razón deciden abandonar los trenes que aún tienen útiles - y cuanta impedimenta les entorpece la marcha — fraccionar sus ya menguadas tropas con el fin de poderse desplazar con rapidez, internarse en la zona montañosa de Puebla y escapar hacia Querétaro. El Presidente despide al escuadrón del Colegio Militar, que tan brillantemente se había distinguido en las acciones guerreras, y se queda con una escolta de quinientos hombres.

Inicia su «via crucis» particular, camino de Tlaxcalantongo, acosado por las fuerzas rebeldes que le pisan los talones. El 17 de mayo El Siglo Futuro anuncia ya el prendimiento de Cándido Aguilar, junto con la derrota definitiva de las fuerzas carrancistas en Rinconada (en realidad Aljibes, ocurrida el 14 de mayo), la huida de Carranza con quinientos jinetes y la captura de «más de 2000 prisioneros, 24 trenes, cuatro cañones, 200 ametralladoras, numerosos automóviles y gran cantidad de municiones para los revolucionarios». Y el día siguiente varios periódicos españoles se hacen eco de estas noticias y las aumentan ${ }^{37}$. Los mensajes sobre el paradero de Carranza y su situación son confusos, aunque lo sitúan en la zona montañosa del Estado de Puebla, próxima al distrito de Zacatlán, donde los Cabrera tenían su solar. Los tres últimos días de su vida transcurren en continua incertidumbre, entre abundantes lluvias y caminos intransitables y evitando el encuentro con contingentes armados. El veinte de mayo, «subiendo las cuestas de Patla», se les une al galope el general Rodolfo Herrero, que les ofrece el amparo de su tropa. Mariel, que encabeza la expedición y que lo había amnistiado unos meses antes, respira por fin tranquilo y satisfecho, y parte hacia Xico, dejando a la comitiva presidencial al cuidado de Herrero. A instancias de éste siguen avanzando hasta Tlaxcalantongo, por ser un «lugar muy seguro y estratégico y en donde hallarían bastante que comer y pastura para los caballos». Con un tiempo infernal llegan a media tarde al jacal de Tlaxcalantongo, «una mala ranchería» en expresión de Urquizo, y se instalan de acuerdo con las indicaciones de Herrero, que destina un lugar apartado para el Presidente. Poco después pide permiso para marchar a ver a un hermano suyo que, al parecer, se ha herido accidentalmente, quedando solos el Presidente y sus ayudantes, con las múltiples sospechas sobre la fidelidad de Herrero que los atenazan.

Lo demás es bastante conocido: en la madrugada del 21 de mayo una partida de soldados de Rodolfo Herrero, emboscados en la parte posterior de la choza del Presidente, hacen fuego graneado sobre el lugar donde calculan que está su cuerpo, mientras profieren gritos de ¡vivas! a Obregón y a Peláez, y de ¡mueras! a Carranza e intiman a la rendición, en medio de tremenda oscuridad y sin que nadie pueda reaccionar ante el asalto. Cuando acuden en ayuda del Presidente éste está agonizando, muriendo a las cuatro y veinte de la madrugada.

${ }^{36}$ El combate contra Guadalupe Sánchez les hace ver que su pretensión de enlazar con las fuerzas de Cándido Aguilar en Veracruz era imposible. En palabras de Urquizo, «hasta entonces nos dimos cuenta perfecta, desde el Presidente de la República hasta el último soldado, que estábamos perdidos, obstruido el paso hacia Veracruz: ya sin amigos y batidos encarnizadamente por fuerzas superiores en número y en moral».

${ }^{37}$ El Siglo Futuro, 17 de mayo, p. 2.18 de mayo: El Heraldo de Madrid, p. 1, El Sol, p. 1, y El Siglo Futuro, p. 1: «los revolucionarios se apoderan de parte del bagaje del Presidente y se incautan de archivos y de cantidades de dinero que ascienden a muchos millones de pesos». 
A estas alturas resulta imposible asegurar si Carranza fue asesinado por los soldados de Herrero, o si, viéndose herido en una pierna e imposibilitado de huir, decidió suicidarse antes de caer en manos de sus enemigos. Los propios testimonios aportados por sus ayudantes son contradictorios ${ }^{38}$. Es cierto que dichos testimonios pudieron ser arrancados bajo coacción y en peligro de muerte, pero ninguno lo rectificó ni siquiera muchos años después. También lo es que no se practicó una autopsia formal y con todos los requisitos y que los testimonios del Dr. Sánchez Pérez y del Dr. Millán, oficialmente enviado por Obregón, fueron antitéticos ${ }^{39}$.

En cualquier caso, sorprende comprobar la celeridad con que circularon las más variadas versiones sobre su muerte, aún en un mismo periódico, aunque todas ellas pueden reducirse a la disyuntiva en que todavía se mantiene dividida la crítica: asesinato o suicidio. Es verdad que en las noticias sobre su asesinato cupieron numerosas combinaciones, que van desde la escueta referencia sin confirmar hasta la muerte con detalles, como que fuera macheteado por Herrero tras una agria querella entre ambos ${ }^{40}$. Pero la realidad es que se suceden en cascada los anuncios de su asesinato y de diez personalidades más de su Estado Mayor ${ }^{41}$, de su muerte en combate ${ }^{42}$ y de su suicidio ${ }^{43}$, junto con los de los presuntos autores del crimen: el sargento Contreras ${ }^{44}$; las mismas tropas a las que se rindió $^{45}$; el general Herrero ${ }^{46}$; o sus propios soldados ${ }^{47}$.

Con la misma rapidez se descartaron las noticias sobre las muertes de los diez miembros de su Estado Mayor y sobre el sargento Contreras, para concentrarse en la indudable responsabilidad de Rodolfo Herrero, en la hipótesis del suicidio, e incluso en la de su

${ }^{38}$ Un resumen ajustado de esta cuestión puede encontrarse en Krauze, 1986, pp. 6-10(repetido en 1987 , pp. 152-172), aunque al final parezca decantarse por la hipótesis del suicidio: «Con todo, el enigma persiste. ¿Cuál es la hipótesis correcta? ¿Murió Carranza balaceado desde afuera del jacal o -como es más probableviéndose herido e inmovilizado tuvo el valor de apurar el cáliz tomando al destino literalmente en sus manos para ser muerto pero no vencido?» (las negritas son nuestras). Urquizo (1931, repetido en 1959, pp. 45-57 y 1995, pp. 219-224) que no fue testigo presencial, afirma que Carranza fue asesinado y que la versión del suicidio fue una patraña urdida por Herrero, quien obligó a Suárez, a Amador y a Aguirre Berlanga a firmarla. Carranza Castro, 1977 sigue a Urquizo en esta cuestión. Taracena, 1963, pp. 311-318, aboga por el suicidio de Carranza ante la inconsistencia -para él- de las versiones que lo juzgan asesinato. El mismo Cabrera, pese a afirmar que «todas las presunciones de suicidio son absurdas» termina concediendo esta posibilidad: «Y si se suicidó realmente...»

${ }^{39}$ Carranza Castro, 1977, pp. 554-556, afirma que Obregón presionó al Dr. Sánchez Pérez para que cambiara su testimonio y que, al no conseguirlo, hizo intervenir al Dr. Millán; pero el tono hagiográfico del libro y su parentesco con el Presidente muerto restan fiabilidad a su afirmación.

4026 de mayo: La Correspondencia de España, p. 6; El País, p. 3.27 de mayo: ABC, p. 19; El Imparcial, p. 2; El Siglo Futuro, p. 1; y El Sol, p. 1. Lo curioso es que todos estos periódicos lo dicen tomar de «fuente fidedigna».

4123 de mayo: El Imparcial, p. 1; El País, p. 1; El Sol, p. 1; La libertad, p. 1.24 de mayo: ABC, pp. 8 y 13; La Correspondencia de España, p. 2; La Época, p. 2; El Siglo Futuro, p. 1; y La Correspondencia Militar, p. 2.

${ }^{42} 23$ de mayo: $A B C$, pp. 8 y 13; El Sol, p. 1; 24 de mayo: La Época, p. 1; La Acción, p. 1. 25 de mayo: $A B C$, p. 15; El Globo, p. 1. 27 de mayo: El Siglo Futuro, p. 1.

${ }^{43} 26$ de mayo: ABC, p. 16; La Correspondencia de España, p. 6; La Época, p. 1; El Imparcial, p. 3; El Heraldo de Madrid, p. 1; y La Libertad, p. 5.27 de mayo: La Libertad, p. 1.

${ }^{44} 24$ de mayo: La Correspondencia de España, p. 2; La Correspondencia Militar, p. 2.25 de mayo: ABC, p. 15; y El Imparcial, p. 1.

${ }^{45}$ La Correspondencia de España, 24 de mayo, p. 2; 25 de mayo: ABC, p. 15; y El Sol, p. 7.

4624 de mayo: $A B C$, pp. 8 y 13; La Época, p. 2.25 de mayo $A B C$, p. 15; El Imparcial, p. 1, y El Globo, p. 1. 26 de mayo: El Imparcial, p. 3; La Libertad, p. 5; y El País, p. 3 . El 27 de mayo, El Imparcial, p. 2; y El Sol, p. 1. Y La Época, 28 de mayo, p. 2.

4725 de mayo: ABC, p. 15; La Época, p. 2; La Libertad, p. 4; y La Correspondencia Militar, p. 1. 
muerte a manos de sus soldados. Esta última interpretación fue sustentada con firmeza por el general Obregón, quien acusó a los allegados de Carranza de complicidad en el asesinato por no haberlo defendido de sus atacantes hasta el final, según podría desprenderse del hecho de que ninguno de ellos hubiera sido herido en la balacera nocturna. Los generales de Carranza se defendieron de tan insólita acusación aclarando cómo se llevó a cabo la fechoría de Herrero y rechazando por absurda la hipótesis del suicidio ${ }^{48}$. A pesar de ello, Urquizo, Murguía, Montes y Barragán tuvieron que comparecer en julio de 1920 ante un Tribunal Federal para ser juzgados por «complicidad en el asesinato del ex presidente» y por «haberse apropiado de importantes sumas pertenecientes al Gobierno en el momento en que el general Carranza emprendió la fuga» ${ }^{49}$.

En cuanto a la responsabilidad del general Herrero en el magnicidio de Tlaxcalantongo y a la hipótesis del suicidio, profundamente interrelacionadas, no podemos descartar completamente ninguna de las dos versiones. Desde luego la gradación de motivos incriminatorios en la traición de Tlaxcalantongo (las continuas protestas de fidelidad a Mariel y a Carranza, la asistencia solícita a éste, el empeño en pernoctar en Tlaxcalantongo, la elección de una choza apartada para el Presidente, las sospechas de Urquizo, las palabras proféticas de Carranza sobre Miramón, la presunta herida del hermano de Rodolfo Herrero, que lo hace ausentarse del mísero lugar, la llegada nocturna del oficial con noticias de Mariel y el eco de los estampidos en medio del sueño tranquilizador) hacen del general Herrero el responsable directo de la muerte de Carranza. De hecho la temprana versión oficial del gobierno provisional mexicano, transmitida al Consulado de México en España y recogida por la prensa española ${ }^{50}$, lo consideró culpable de homicidio y, entre la opinión pública mexicana, se tenía la certeza de que el general Herrero sería fusilado. Así es que su testimonio sobre el suicidio del Presidente carecía de fuerza moral y de legitimidad, a pesar de que fuera ratificado por quienes acompañaron a Carranza en su último tránsito, porque siempre quedaba la sospecha de que arrancó la declaración de Aguirre, Amador y Suárez bajo fortísima coacción.

Con todo, Herrero mantuvo siempre que Carranza se había suicidado, desesperado por la derrota, al comprobar que había sido rodeado por un enemigo que lo intimaba a la rendición. Ya el 26 de mayo ABC, La Correspondencia de España, La Época y El Imparcial $^{51}$ recogen sus declaraciones al general Pablo González, así como su disposición para trasladarse a México y aportar las pruebas que obran en su poder con el fin de deshacer «las acusaciones lanzadas» contra él. Y dos días después El Siglo Futuro notifica que se rinde a las tropas del Gobierno Provisional, con la intención de comparecer ante un Tribunal Militar $^{52}$. El 11 de junio El Imparcial anuncia ${ }^{53}$ que Herrero declara bajo juramento a los jueces que el expresidente se suicidó con su propia pistola.

${ }^{48}$ El Siglo Futuro, 26 de mayo, p. 2; El Imparcial, 27 de mayo, p. 1; y El Globo, 28 de mayo, p. 1. La relación más detallada sobre la traición de Tlaxcalantongo la ofrece el general Aguirre, Ministro de la Gobernación de Carranza a El Universal de México, de donde la toman El Sol, 20 de junio, p. 1 y El Siglo Futuro, 21 de junio, p. 1.

${ }^{49}$ El Imparcial, 9 de julio, p. 2.

${ }^{50}$ La Época y El Siglo Futuro, 28 de mayo, p. 2 . Y el día siguiente (29 de mayo): ABC, p. 13; El Imparcial, p. 2; La Correspondencia Militar, p. 3; y La Acción, p. 1. Pero derivaron hacia «una venganza personal».

${ }^{51}$ Respectivamente pp. 16, 6, 1 y 3.

52 El Siglo Futuro, 28 de mayo, p. 2.

${ }^{53}$ El Imparcial, 11 de junio, p. 2. 
Pero todo el mundo creía en su culpabilidad. Quizá, por eso, resultó sorprendente la decisión final del tribunal de dejarlo libre por falta de pruebas, con la protesta expresa del auditor general del ejército, que vio en este acto una flagrante violación de la ley por parte del tribunal al apoyar de este modo el ataque a un Presidente constitucional. Más sorprendente resulta el que el ejército no lo separara de sus filas hasta el 30 de diciembre de 1920, y que después siguiera utilizándolo en actividades diversas hasta bien avanzada la década del treinta (1937).

¿Qué movió a Obregón a no castigar severamente a Herrero? ¿Cuántos pudieron estar implicados en el asesinato de Carranza? Los indicios apuntan al mismo Obregón; también a Lázaro Cárdenas ${ }^{54}$, a la sazón coronel que mandaba el contingente obregonista próximo a Tlaxcalantongo. Incluso se llega a hablar de una conspiración de las compañías petroleras de los Estados Unidos para acabar con Carranza ${ }^{55}$. No es extraño que el gobierno estadounidense presionara al gobierno de México y nombrara por su cuenta una comisión propia con el fin de esclarecer los hechos y desvanecer las acusaciones que circulaban en su contra ${ }^{56}$.

Pero por encima de cualquier otra noticia, la prensa española muestra de forma indirecta la omnímoda presencia del general Obregón y el protagonismo que le corresponde en este momento. Nada más conocer públicamente la muerte de Carranza lanza una proclama condenando severamente el atentado y asegura que «el peso de la ley» caerá sobre el autor (o los autores) del mismo ${ }^{57}$. Cuando se confirma la autoría de Herrero, manda en su persecución un destacamento militar de dos mil soldados, a la par que difunde la idea de que el asesinato se debe a una «venganza personal» ${ }^{58}$. Al parecer, intenta sobornar a los médicos que hacen la autopsia para que sostengan la hipótesis del suicidio ${ }^{59}$, a la vez que acusa de complicidad —o de cobardía — a los militares leales al asesinado presidente. Y a requerimientos suyos se constituye una comisión de reporteros procedentes de El Universal, El Excelsior, El Heraldo y El Demócrata, con el fin de que investigue «de un modo preciso y que no deje lugar a dudas, las causas de la muerte del expresidente

${ }^{54}$ Richmond, 1986, pp. 319-320. Ver también Moguer Flores, 2002, p. 132.

55 La prensa española fue muy receptiva a esta opinión, como muestran $A B C$ (21 de mayo, p. 15), El Imparcial (26 de mayo, p. 3), El Siglo Futuro (26 de mayo, p. 2), La Correspondencia de España, (27 de mayo, p.2), El Globo (28 de mayo, p. 1), El Sol (8 de junio, p. 1). Concluye El Imparcial (15 de julio, p. 1) con un artículo de opinión de M. Ciges Aparicio, titulado «El petróleo y el porvenir del mundo». Con todo, la mayor beligerancia se percibe en los artículos que bajo el rubro de «Vida americana», publica Alfonso de L. Sarralbo y Palacio en La Ilustración Española y Americana, los días 22 de abril, p. 12; 30 de abril, p. 13; 8 de junio, p. 9; y 15 de junio, p. 4. Como respuesta a esta opinión, interesa el artículo de El País, «Méjico y Rusia», 24 de junio, p. 1, en el que destaca sobre todo en ambos países «violencia, caudillaje, golpes de mano», como los causantes de la última revuelta mexicana.

${ }^{56}$ La Época, 2 de junio, p. 3. Sarralbo y Palacio se hace eco irónicamente de esta comisión para desprestigiarla en su artículo del 8 de junio, citado en la nota anterior: «Cuando hasta los gatos saben la ojeriza que contra el asesinado Carranza tenía Norte-América, porque le ataba corto en sus ambiciones insanas, ahora, eterna fariseo, nombra por medio de su Alta Cámara, una Comisión compuesta de un senador y de un miembro del Tribunal Supremo para esclarecer responsabilidades sobre la muerte de aquel gran estadista...»(p. 9).

5724 de mayo: La Correspondencia de España, p. 2, La Época, p. 2, y La Correspondencia Militar, p. 2. El Imparcial, 25 de mayo, p. 1.

${ }_{58} 26$ de mayo: La Correspondencia de España, p. 6, El País, p. 3, y La Libertad, p. 5.27 de mayo: El Imparcial, p. 2, El Siglo Futuro, p. 1, y El Sol, p. 1

${ }^{59}$ Ver nota 37 de este trabajo y Richmond, 1986, p. 319. 
Carranza ${ }^{60}$. Y todo ello sin descuidar las relaciones internacionales, en especial con el poderoso vecino del Norte, al que da todo tipo de seguridades sobre sus ciudadanos y empresas en territorio mexicano, a la par que muestra su enorme pesar por el magnicidio ocurrido. Es posible afirmar que por estas fechas no se hace nada en México sin permiso suyo $^{61}$. Con una abrumadora mayoría en el Congreso, pide al Senado que nombre a un juez de la Corte Suprema para revisar la muerte de Carranza. El resultado no pude ser más previsible. Y lo resume el enunciado de La Correspondencia de España cuando informa sobre él: «Entre todos lo mataron» ${ }^{62}$. Ironía que compendia perfectamente el sentir de la prensa española. Extractada en lo esencial, la noticia dice: «Reunidos los del Tribunal Federal, tras diez horas de discusión, no han logrado ponerse de acuerdo en la forma y el origen de la muerte de Carranza».

En conclusión, podemos afirmar que en la prensa española primó en este asunto la información sobre la opinión. Recogió con bastante fidelidad los dramáticos sucesos que desembocaron en el magnicidio de Tlaxcalantongo, así como las diversas interpretaciones que surgieron del seno de la sociedad mexicana para explicar tan luctuoso episodio. Los diferentes periódicos transmitieron las abundantes noticias propagadas desde las esferas del gobierno provisional; pero también se hicieron eco, si bien de forma mitigada, de las angustiosas pero firmes declaraciones emitidas por la descabezada oposición carrancista. Los escasos artículos de opinión hay que leerlos en clave de lectura política española y desde una óptica abiertamente anti-estadounidense. Y recogen el sentir crítico de los autores contra la «nueva revolución» triunfante. Por el contrario todos elogian la figura del Presidente muerto, como un estadista ejemplar, patriota, independiente y celoso de los intereses económicos mexicanos, que en estos momentos, ven peligrar.

\section{BiBLIOGRAFÍA}

Azuela, M., Las tribulaciones de una familia decente, en Obras completas, México, FCE, 1976, I, pp. 419-566.

Beteta, R., Camino a Tlaxcalantongo, México, FCE, 1961.

Cabrera, L., La herencia de Carranza, en Obras completas, México, Ediciones Oasis, 1975, vol. III, pp. 441-545.

Carranza Castro, J., Origen, destino y legado de Carranza, México, B. Costa-Amic Editor, 1977.

Fabela, J. E. de, Testimonios sobre los asesinatos de don Venustiano Carranza, México, Editorial Jus, 1971, t. XVIII y XIX. Dentro de la colección de Fabela, I., y Fabela, J. E. de, Documentos históricos de la Revolución Mexicana, México, Editorial Jus-FCE, 1960-1973.

Gobierno E. Coahuila, Venustiano Carranza. Testimonios, Saltillo, Coahuila, Gobierno del Estado de Coahuila, 1995.

${ }^{60}$ La Época, 27 de mayo, p. 3.28 de mayo: El Imparcial, p. 2, y El País, p. 1. El 2 de junio notifican la constitución de dicha comisión La Correspondencia Española, p. 2, La Época, p. 1, El Imparcial, p. 3, y El Siglo Futuro, p. 1. Es muy probable que su intención fuera acallar las críticas de la prensa mexicana.

${ }^{61}$ Es básica para este apartado «Mi entrevista con el general Obregón», de Wenceslao Blasco, realizada en mayo de 1920, aunque publicada en $A B C$ el 19 de junio, pp. 5-6, en que muestra cómo desde el hotel St. Francis de México, erigido en su cuartel general, Obregón manda, ejecuta, y diseña todos los movimientos de los revolucionarios.

6214 de junio, p. 2. Al día siguiente recogen la misma noticia La Época, p. 1, y El Imparcial, p. 2. 
Krauze, E., «La noche de Tlaxcalantongo», Vuelta, II. , febrero de 1986, pp. 6-10. Puente entre siglos. Venustiano Carranza, México, FCE, 1987, pp. 152-172.

Moguer Flores, J., Venustiano Carranza, México, Planeta de Agostini, 2002.

Richmond, D. W., La lucha nacionalista de Venustiano Carranza, 1883-1920, México, FCE, 1986.

Suárez, Ignacio G., Carranza, el forjador del México actual, México, Costa-Amic Editores, 1965.

Taracena, A., Venustiano Carranza, México, Editorial Jus, 1963.

Urquizo, F. L., México- Tlaxcalantongo. Mayo de 1920, México, Editorial Cultura, 1931.

- Carranza, México, Planilla Lex, I958.

VASCONCELOS, J., La tormenta, México, Editorial Jus, 1958.

\section{Apéndice documental}

\section{$A B C$ :}

13 de abril de 1920, p. 20.

16 de abril de 1920, p. 18.

18 de abril de 1920, p. 17.

21 de abril de 1920, pp. 7 y 15.

23 de abril de 1920, p. 14.

26 de abril de 1920, p. 7.

6 de mayo de 1920, p. 15.

7 de mayo de 1920, p. 13.

9 de mayo de 1920, p. 20.

10 de mayo de 1920, p. 13.

13 de mayo de 1920, p. 20.

14 de mayo de 1920, p. 14.

22 de mayo de 1920, p. 15.

23 de mayo de 1920, p. 17.

24 de mayo de 1920, pp. 7-8 y 13.

25 de mayo de 1920, p. 15.

26 de mayo de 1920, p. 16.

27 de mayo de 1920, p. 19.

29 de mayo de 1920, p. 13.

30 de mayo de 1920, p. 19.

31 de mayo de 1920, p. 19.

5 de junio de 1920, p. 11.

6 de junio de 1920, pp. 4-6.

7 de junio de 1920, pp. 4-6. Repite el artículo del día anterior.

10 de junio de 1920 , p. 4.

15 de junio de 1920, p. 19.

18 de junio de 1920 , pp. 7-8.

19 de junio de 1920, pp. 5-6.

24 de junio de 1920, pp. 7-8.

25 de junio de 1920, p. 11. 
29 de junio de 1920, pp. 4-5.

2 de julio de 1920, pp. 4-6.

9 de julio de 1920, pp. 9-10.

29 de julio de 1920, p. 19.

\section{La Correspondencia de España:}

15 de abril de 1920 , p. 2.

16 de abril de 1920, p. 2.

24 de abril de 1920, p. 1.

29 de abril de 1920, p. 2.

4 de mayo de 1920 , p. 6.

6 de mayo de 1920, p. 2.

7 de mayo de 1920, p. 2.

8 de mayo de 1920, p. 2.

12 de mayo de 1920 , p. 1.

24 de mayo de 1920 , p. 2.

26 de mayo de 1920, p. 6.

27 de mayo de 1920, p. 2.

29 de mayo de 1920, p. 6.

2 de junio de 1920, pp. 2 y 7.

14 de junio de 1920, p. 2.

12 de julio de 1920, p. 2.

\section{La Época:}

15 de abril de 1920, p. 1. 16 de abril de 1920, p. 1. 19 de abril de 1920, p. 1. 23 de abril de 1920, p. 1. 26 de abril de 1920, p. 1. 28 de abril de 1920, p. 1. 6 de mayo de 1920, p. 1. 11 de mayo de 1920, p. 1 . 12 de mayo de 1920, p. 3. 13 de mayo de 1920, p. 2. 17 de mayo de 1920 , p. 3. 18 de mayo de 1920, p. 2. 24 de mayo de 1920, p. 2. 25 de mayo de 1920 , p. 2. 26 de mayo de 1920, p. 1. 27 de mayo de 1920, p. 3. 28 de mayo de 1920, p. 2. 2 de junio de 1920, pp. 1 y 3 .

15 de junio de 1920, p. 1 . 26 de julio de 1920, p. 4. 


\section{La Ilustración Española y Americana:}

15 de abril de 1920, p. 6.

22 de abril de 1920, p. 12.

30 de abril de 1920, p. 13

8 de junio de 1920, p. 9.

15 de junio de 1920, p. 4.

\section{El Imparcial:}

7 de mayo de 1920, p. 1.

9 de mayo de 1920, p. 1.

12 de mayo de 1920 , p. 2.

13 de mayo de 1920 , p. 1.

23 de mayo de 1920, pp. 1 y 3 .

25 de mayo de 1920, p. 1.

26 de mayo de 1920, pp. 1 y 3.

27 de mayo de 1920, p. 2.

28 de mayo de 1920, p. 2.

2 de junio de 1920, p. 1

11 de junio de 1920, p. 3.

15 de junio de 1920, p. 2.

9 de julio de 1920, p. 2.

15 de julio de 1920, p. 1.

\section{Nuevo Mundo:}

28 de mayo de 1920, p. 18.

\section{El Globo:}

24 de abril de 1920, p. 2.

30 de abril de 1920, p. 2.

7 de mayo de 1920, p. 3 .

8 de mayo de 1920 , p. 1 .

11 de mayo de 1920 , p. 1.

12 de mayo de 1920, p. 3.

14 de mayo de 1920, pp. 1 y 3 .

24 de mayo de 1920, p. 3.

25 de mayo de 1920, pp. 1 y 3 .

26 de mayo de 1920, p. 1.

28 de mayo de 1920, p. 1.

29 de mayo de 1920, p. 2.

30 de mayo de 1920 , p. 3.

\section{El Siglo Futuro:}

15 de abril de 1920, p. 1.

23 de abril de 1920, p. 1.

24 de abril de 1920, p. 2. 
5 de mayo de 1920, p. 1.

6 de mayo de 1920, p. 1.

7 de mayo de 1920, p. 1 .

8 de mayo de 1920, p. 1.

10 de mayo de 1920 , p. 1.

11 de mayo de 1920, p. 1.

12 de mayo de 1920, p. 2.

14 de mayo de 1920 , p. 1.

17 de mayo de 1920, p. 2.

18 de mayo de 1920, p. 1 .

24 de mayo de 1920, p. 1.

26 de mayo de 1920, p. 2.

27 de mayo de 1920, p. 1.

28 de mayo de 1920, p. 2.

31 de mayo de 1920, p. 2.

2 de junio de 1920, p. 1.

21 de junio de 1920, p. 1.

\section{La Correspondencia Militar:}

14 de mayo de 1920, p. 2. 24 de mayo de 1920, p. 2. 25 de mayo de 1920, p. 1. 26 de mayo de 1920, p. 2. 29 de mayo de 1920, p. 3.

\section{El País:}

11 de mayo de 1920, p. 2. 13 de mayo de 1920, p. 1. 14 de mayo de 1920, p. 2. 16 de mayo de 1920, p. 1. 23 de mayo de 1920 , p. 1. 26 de mayo de 1920 , p. 3. 28 de mayo de 1920, p. 1. 30 de mayo de 1920, p. 2. 24 de junio de 1920, p. 1.

\section{Mundo Gráfico:}

26 de mayo de 1920, p. 7.

2 de junio de 1920, p. 5.

\section{El Heraldo de Madrid}

8 de mayo de 1920, p. 1. 12 de mayo de 1920, p. 2. 18 de mayo de 1920, p. 1. 26 de mayo de 1920, pp. 1 y 4. 
31 de mayo de 1920, p. 2.

\section{La Voz:}

8 de julio de 1920, p. 1 .

\section{El Sol:}

16 de abril de 1920, p. 9. 18 de abril de 1920, p. 7. 23 de abril de 1920, p. 7. 24 de abril de 1920, p. 7. 29 de abril de 1920, p. 7. 9 de mayo de 1920, p. 1. 11 de mayo de 1920, p. 1 . 12 de mayo de 1920, pp. 3 y 7. 13 de mayo de 1920, p. 7. 14 de mayo de 1920 , p. 1 . 16 de mayo de 1920, p. 1. 18 de mayo de 1920, p. 1 . 20 de mayo de 1920 , p. 7. 22 de mayo de 1920, p. 7. 23 de mayo de 1920, p. 1. 25 de mayo de 1920, p. 7. 27 de mayo de 1920 , p. 1. 28 de mayo de 1920, p. 3. 30 de mayo de 1920, p. 15. 8 de junio de 1920, p. 1. 20 de junio de 1920, p. 1.

\section{La Libertad:}

15 de abril de 1920, p. 3. 29 de abril de 1920, p. 3. 7 de mayo de 1920, p. 1 . 11 de mayo de 1920, p. 1. 12 de mayo de 1920 , p. 1. 14 de mayo de 1920, p. 5. 23 de mayo de 1920, p. 1 . 25 de mayo de 1920, p. 4. 26 de mayo de 1920, p. 5. 27 de mayo de 1920, p. 1. 23 de julio de 1920, p. 1 .

\section{España:}

24 de abril de 1920, p. 7.

22 de mayo de 1920, pp. 23-25.

5 de junio de 1920, p. 12. 


\section{La Acción:}

6 de mayo de 1920, p. 3.

7 de mayo de 1920, p. 1.

11 de mayo de 1920 , p. 1.

14 de mayo de 1920 , p. 1.

17 de mayo de 1920, p. 3.

24 de mayo de 1920, p. 1.

26 de mayo de 1920, p. 1.

29 de mayo de 1920 , p. 1.

31 de mayo de 1920, p. 2.

\section{Vida Marítima:}

30 de abril de 1920, p. 4.

30 de mayo de 1920 , p. 5.

10 de julio de 1920, p. 3 . 
